OPEN ACCESS

Edited by:

Ulrike Garscha,

Friedrich Schiller University Jena,

Germany

Reviewed by:

Cristina López-Vicario,

Hospital Clínic de Barcelona,

Spain

Giustino Orlando,

Università degli Studi G. d'Annunzio

Chieti e Pescara,

Italy

*Correspondence:

Filip Bergqvist

Bergqvist.Filip@gmail.com

Louise Berg

Louise.Berg@ki.se

Specialty section:

This article was submitted to Inflammation Pharmacology,

a section of the journal

Frontiers in Pharmacology

Received: 19 February 2020 Accepted: 20 April 2020

Published: 06 May 2020

Citation:

Bergqvist $F$, Sundström $Y$, Shang M-M, Gunnarsson I, Lundberg IE, Sundström $M$, Jakobsson P-J and Berg $L$

(2020) Anti-Inflammatory

Properties of Chemical Probes in

Human Whole Blood: Focus on

Prostaglandin $E_{2}$ Production.

Front. Pharmacol. 11:613.

doi: 10.3389/fphar.2020.00613

\section{Anti-Inflammatory Properties of Chemical Probes in Human Whole Blood: Focus on Prostaglandin $\mathrm{E}_{2}$ Production}

\author{
Filip Bergqvist ${ }^{1,2 *}$, Yvonne Sundström ${ }^{1,2}$, Ming-Mei Shang ${ }^{1,2}$, Iva Gunnarsson ${ }^{1}$, \\ Ingrid E. Lundberg ${ }^{1}$, Michael Sundström ${ }^{1,2}$, Per-Johan Jakobsson ${ }^{1,2}$ and Louise Berg ${ }^{1,2 *}$ \\ ${ }^{1}$ Division of Rheumatology, Department of Medicine, Solna, Karolinska Institutet, and Karolinska University Hospital, \\ Stockholm, Sweden, 2 The Structural Genomic Consortium (SGC), Karolinska Institutet, Stockholm, Sweden
}

We screened 57 chemical probes, high-quality tool compounds, and relevant clinically used drugs to investigate their effect on pro-inflammatory prostaglandin $E_{2}\left(P_{G} E_{2}\right)$ production and interleukin-8 (IL-8) secretion in human whole blood. Freshly drawn blood from healthy volunteers and patients with systemic lupus erythematosus (SLE) or dermatomyositis was incubated with compounds at 0.1 or $1 \mu \mathrm{M}$ and treated with lipopolysaccharide (LPS, $10 \mu \mathrm{g} / \mathrm{ml}$ ) to induce a pro-inflammatory condition. Plasma was collected after $24 \mathrm{~h}$ for lipid profiling using liquid chromatography tandem mass spectrometry (LC-MS/MS) and IL-8 quantification using enzyme-linked immunosorbent assay (ELISA). Each compound was tested in at least four donors at one concentration based on prior knowledge of binding affinities and in vitro activity. Our screening suggested that PD0325901 (MEK-1/2 inhibitor), trametinib (MEK-1/2 inhibitor), and selumetinib (MEK-1 inhibitor) decreased while tofacitinib (JAK inhibitor) increased PGE 2 production. These findings were validated by concentration-response experiment in two donors. Moreover, the tested MEK inhibitors decreased thromboxane $B_{2}\left(T_{X B}\right)$ production and IL-8 secretion. We also investigated the lysophophatidylcholine (LPC) profile in plasma from treated whole blood as these lipids are potentially important mediators in inflammation, and we did not observe any changes in LPC profiles. Collectively, we deployed a semi-high throughput and robust methodology to investigate anti-inflammatory properties of new chemical probes.

\section{Keywords: prostaglandin $E_{2}$, whole blood assay, interleukin-8, inflammation, drug screen}

\section{HIGHLIGHTS}

- Inhibitors for MEK decreased $\mathrm{PGE}_{2}$ and $\mathrm{TXB}_{2}$ production

- Inhibitors for MEK and ERK decreased IL-8 secretion

- JAK inhibitor tofacitinib increased $\mathrm{PGE}_{2}$ and $\mathrm{TXB}_{2}$ production 


\section{INTRODUCTION}

Inflammation is a highly controlled immune response to eliminate the cause of tissue injury or infection and to initiate tissue repair back to homeostasis via resolution (Nathan, 2002; Buckley et al., 2013). However, inflammation is not always terminated. Unresolved inflammation causes persistent pain, tissue degeneration, and loss of function. In particular, inflammatory responses drive many autoimmune diseases (McInnes and Schett, 2011) and inflammation is a hallmark of cancer (Hanahan and Weinberg, 2011). Thus, there is a great need for new therapies that are anti-inflammatory and safe.

Prostaglandin $\mathrm{E}_{2}\left(\mathrm{PGE}_{2}\right)$ is a potent lipid mediator of inflammation and immune responses, and $\mathrm{PGE}_{2}$ is a central mediator of pain, edema, and cartilage erosion typically observed in the joints of rheumatoid arthritis patients (Akaogi et al., 2012; Fattahi and Mirshafiey, 2012). In addition, $\mathrm{PGE}_{2}$ is a promotor of the immunosuppressive tumor microenvironment with major impact on tumor progression (Wang and Dubois, 2010; Hanahan and Weinberg, 2011; Ricciotti and Fitzgerald, 2011). During inflammation, $\mathrm{PGE}_{2}$ is synthesized via conversion of arachidonic acid by cyclooxygenases (COX-1 and COX-2) into unstable $\mathrm{PGH}_{2}$ that is further metabolized by the inducible terminal synthase microsomal prostaglandin E synthase-1 (mPGES-1) to generate $\mathrm{PGE}_{2}$. Multiple non-steroidal antiinflammatory drugs (NSAIDs) exist in clinical practice that unselectively decrease $\mathrm{PGE}_{2}$ production via inhibition of $\mathrm{COX}$, but these drugs are all associated with adverse effects. Hence, selective inhibition of $\mathrm{PGE}_{2}$ production with small molecule inhibitors could therefore be a desirable therapeutic strategy in inflammation and cancer (Bergqvist et al., 2020).

Interleukin-8 (IL-8) is a potent chemoattractant and activator of neutrophils. IL- 8 signaling is implicated in multiple chronic inflammatory diseases (Russo et al., 2014) and cancer (Waugh and Wilson, 2008). For example, a recent meta-analysis concluded that patients suffering from systemic lupus erythematosus (SLE) have increased levels of circulating IL-8 (Mao et al., 2018). Patients with central neuropsychiatric SLE have increased concentration of IL- 8 in cerebrospinal fluid compared to patients with non-central neuropsychiatric SLE (Yoshio et al., 2016). IL-8 is also associated with renal damage and pulmonary fibrosis in SLE patients (Lit et al., 2006; Nielepkowicz-Goździńska et al., 2014). Given that IL-8 is a stimulant for neutrophil activation, which plays a significant role in the pathogenesis of SLE (Kaplan, 2011), targeting IL-8 secretion or signaling could constitute a therapeutic strategy for SLE. A similar role of neutrophils and net formation has been reported in patients with dermatomyositis (DM) (Zhang et al., 2014; Peng et al., 2018). In cancer, IL-8 is highly expressed in several types of cancer tissues (David et al., 2016) and serum concentration of IL-8 correlates with tumor burden (Alfaro et al., 2017). The tumor-favoring actions of IL- 8 include promotion of angiogenesis, increased survival of cancer stem cells, and attraction of myeloid cells that indorse the immunosuppressive tumor microenvironment (Alfaro et al., 2017).

In this study, we aimed to evaluate the effect of 57 chemical probes, high-quality tool compounds, and relevant control drugs on eicosanoid production and IL-8 secretion in human whole blood. A chemical probe is defined as "... a selective smallmolecule modulator of a protein's function that allows the user to ask mechanistic and phenotypic questions about its molecular target in biochemical, cell-based or animal studies" (Arrowsmith et al., 2015), and these compounds follow the criteria of in vitro potency $\left(\mathrm{IC}_{50}\right.$ or $\mathrm{Kd}<100 \mathrm{nM}$ ), high selectivity versus other protein subfamilies ( $>30$-fold), and on-target cell activity at 1 $\mu \mathrm{M}$. The chemical probes and other high-quality tool compounds included are mainly epigenetic modulators and kinase inhibitors that were produced in academic collaborations or donated by pharmaceutical companies within the Structural Genomic Consortium (SGC, www.thesgc.org), which aims to investigate novel targets for drug development in open science and in collaboration with the pharmaceutical industry. These inhibitors were tested here at one concentration (in triplicates, $\mathrm{n}=4-15$ donors) based on previous knowledge of binding affinities and toxicity in vitro, as assessed using other validated assays in our laboratories (https://ultra-dd.org/tissueplatforms/cell-assay-datasets).

\section{MATERIALS AND METHODS}

\section{Ethical Approval and Consent to Participate}

Ethical approval for this study was granted by local research ethics committee at Karolinska University hospital (Dnr 02-196) and the Regional Ethical Review Board in Stockholm (Dnr 2015/ 2001-31/2). Full informed consent according to the Declaration of Helsinki was obtained from all patients.

\section{Collection of Blood}

Peripheral venous blood was drawn from 10 females and 6 males, aged between 27 and 81 years. Healthy controls $(n=4)$ and two patient groups were included: SLE $(n=9)$ and DM $(n=3)$. Patients with diagnosis SLE or DM and aged 18 or older were recruited from the Rheumatology Clinic at Karolinska University Hospital. Patients with ongoing treatment including Sendoxan (cyclophosphamide) and Benlysta (belimumab) or with kidney failure as defined by present dialysis or previous kidney transplantation were excluded. Disease activity measurements were not obtained at the time of sampling. For healthy control and patients characteristics, see Supplementary Table 1. The blood was collected in tubes containing sodium heparin (1000 $\mathrm{U} / \mathrm{ml})$.

\section{Inhibitors}

The inhibitors (chemical probes and other high-quality tool compounds) tested here were obtained through the SGC (www.thesgc.org) and supplied by different distributers (Supplementary Table 2). Inhibitors and control drugs (Supplementary Table 2) were reconstituted at $10 \mathrm{mM}$ in DMSO (D2250, Sigma-Aldrich), aliquoted in Eppendorf tubes or 96 -well plates, and kept at $-80^{\circ} \mathrm{C}$. A fresh aliquot was used at each experiment. Diclofenac (dual COX-1/2 inhibitor) was used 
as positive control for inhibition of prostanoid production. Lipopolysaccharide (LPS; L6529, Sigma-Aldrich) was reconstituted in phosphate-buffered saline (PBS) (D8537, Sigma-Aldrich) to a final concentration of $0.1 \mathrm{mg} / \mathrm{ml}$ and kept at $+8^{\circ} \mathrm{C}$.

\section{Whole Blood Assay}

Inhibitors and vehicle control (DMSO) were diluted in PBS at room temperature with no direct light on. The treatments were prepared in $25 \mu \mathrm{l}$ portions to U-shaped 96-well plate and $200 \mu \mathrm{l}$ of freshly drawn heparin blood $(<2 \mathrm{~h}$ at room temperature) was added to the plate. The plate was incubated at $37^{\circ} \mathrm{C}$ for $30 \mathrm{~min}$ and then $25 \mu \mathrm{l}$ of $0.1 \mathrm{mg} / \mathrm{ml}$ LPS in PBS was added followed by pipetting up and down 3 times (final concentration of LPS was 10 $\mu \mathrm{g} / \mathrm{ml})$. The tested concentration for inhibitor was 0.1 or $1 \mu \mathrm{M}$ (Supplementary Table 1). The plate was incubated for $24 \mathrm{~h}$ at $37^{\circ} \mathrm{C}$ and then centrifuged at $3000 \mathrm{~g}$ for $10 \mathrm{~min}$ at $4^{\circ} \mathrm{C}$. Working on ice, $100 \mu \mathrm{l}$ plasma was recovered to a new plate (for prostanoid profiling) and from this $20 \mu \mathrm{l}$ was transferred to a second plate (for IL-8 quantification). The plates were sealed with aluminum foil and stored at $-80^{\circ} \mathrm{C}$.

\section{Extraction of Lipids}

Plasma samples (80-240 $\mu \mathrm{l})$ were thawed on ice and spiked with $50 \mu \mathrm{l}$ deuterated internal standard mix containing 17 ng 6-keto$\mathrm{PGF}_{1 \alpha}-\mathrm{d} 4,8$ ng $\mathrm{PGF}_{2 \alpha}-\mathrm{d} 4,12$ ng $\mathrm{PGE}_{2}-\mathrm{d} 4,8$ ng $\mathrm{PGD}_{2}$-d4, 8 ng thromboxane $\mathrm{B}_{2}\left(\mathrm{TXB}_{2}\right)$-d4, and 8 ng 15 -deoxy- $\Delta 12,14 \mathrm{PGJ}_{2}-\mathrm{d} 4$ (Cayman Chemical Company) prepared in $100 \%$ methanol. Protein precipitation was performed by addition of $800 \mu \mathrm{l}$ $100 \%$ methanol, followed by vortexing, and centrifugation at $3000 \mathrm{~g}$ for $10 \mathrm{~min}$ at $4^{\circ} \mathrm{C}$. The supernatants were collected in a new plate and evaporated under vacuum for $4 \mathrm{~h}$. The evaporated samples $(100-200 \mu \mathrm{l})$ were diluted to $1 \mathrm{ml}$ with $0.05 \%$ formic acid in water and then loaded onto Oasis HLB $1 \mathrm{cc} 30 \mathrm{mg}$ plate (Waters Corporation, USA) that had been pre-conditioned with $1 \mathrm{ml}$ of $100 \%$ methanol and $1 \mathrm{ml}$ of $0.05 \%$ formic acid in water. The plate was washed with $10 \%$ methanol, $0.05 \%$ formic acid in water and lipids were eluted with $100 \%$ methanol. The eluates were dried under vacuum overnight and stored at $-20^{\circ} \mathrm{C}$ until reconstituted in $50 \mu \mathrm{l}$ of $20 \%$ acetonitrile in water prior to analysis with liquid chromatography tandem mass spectrometry (LC-MS/MS).

\section{Lipid Profiling by LC-MS/MS}

Lipids were quantified in negative mode with multiple reaction monitoring method, using a triple quadrupole mass spectrometer (Acquity TQ detector, Waters) equipped with an Acquity H-class UPLC (Waters). Eicosanoid were purchased from Cayman Chemicals and individually optimized for based on precursor ion $\mathrm{m} / \mathrm{z}$, cone voltage, collision energy, and fragment ion $\mathrm{m} / \mathrm{z}$ (Supplementary Table 3). An eicosanoid mix containing all standards of interest was used to check interference in the LCMS/MS analysis. Lysophophatidylcholine (LPC)(14:0) and LPC (18:0) were used to set optimal analytical parameters for quantification of LPCs. Separation of lipids was performed on a $50 \times 2.1$-mm Acquity UPLC BEH C18 column $1.7 \mu \mathrm{m}$ (Waters) with a 12 -min stepwise linear gradient $(20 \%-95 \%)$ at a flowrate of
$0.6 \mathrm{ml} / \mathrm{min}$ with $0.05 \%$ formic acid in acetonitrile as mobile phase $\mathrm{B}$ and $0.05 \%$ formic acid in water as mobile phase A. Data were analyzed using MassLynx software, version 4.1, with internal standard calibration and quantification to external standard curves for prostanoids. LPCs were normalized as area-\% within each injection. Only lipids with peaks intensities of signal-tonoise greater than $10(\mathrm{~S} / \mathrm{N}>10)$ were considered in our data analysis.

\section{Development of Whole Blood Assay}

The whole blood assay was developed to screen for changes in multiple eicosanoids. Each eicosanoid and corresponding deuterated variant were individually optimized in the LC-MS/ MS analysis. A dilution curve containing 6-keto $\mathrm{PGF}_{1 \alpha^{-}} \mathrm{d} 4$, $\mathrm{PGE}_{2}-\mathrm{d} 4, \mathrm{PGD}_{2}-\mathrm{d} 4, \mathrm{PGF}_{2 \alpha}-\mathrm{d} 4, \mathrm{TXB}_{2}-\mathrm{d} 4,15 \mathrm{~d}-\mathrm{PG}_{2}-\mathrm{d} 4, \mathrm{LTB}_{4}$ $\mathrm{d} 4, \mathrm{LTC}_{4}$-d5, LTD 4 -d5, 5-HETE-d8, 12-HETE-d8, 15-HETE-d8, and undeuterated variants of 13-HODE, RvD1, RvD2, 17hydroxy DHA, and protectin DX was spiked into $100 \mu \mathrm{l}$ plasma at different stages throughout the extraction. A dilution curve was spiked in water at the same step. The dilution curve ranged from 0.006 to $1.5 \mathrm{pmol}$ as final amount injected on the column in the LC-MS/MS analysis. This enabled us to investigate the lower limit of quantification (LLOQ), recovery efficacy, and matrix effect for each eicosanoid. The LLOQ injected on column was considered as great $(0.02-0.05 \mathrm{pmol})$, good $(0.1-0.2 \mathrm{pmol})$, or poor $(0.4-1.5 \mathrm{pmol})$. Eicosanoids with great LLOQ were $\mathrm{PGE}_{2}, \mathrm{PGF}_{2 \alpha}, \mathrm{TXB}_{2}, \mathrm{RvD} 1, \mathrm{RvD} 2, \mathrm{LTB}_{4}$, protectin DX, and 13-HODE; good LLOQ were 6-keto $\mathrm{PGF}_{1 \alpha}, \mathrm{PGD}_{2}, 5$-HETE, 15 HETE, and $\mathrm{LTD}_{4}$; poor LLOQ were $15 \mathrm{~d}-\mathrm{PG} \mathrm{J}_{2}, 12-\mathrm{HETE}, 17-$ hydroxy $\mathrm{DHA}$, and $\mathrm{LTC}_{4}$. The extraction recovery rates were $33 \%-125 \%$. The response in plasma compared to $20 \%$ acetonitrile were $52 \%-116 \%$ due to matrix effects. The estimated LLOQ in $100 \mu$ plasma was approximately $1 \mathrm{ng} / \mathrm{ml}$ for the best performing eicosanoids including $\mathrm{PGE}_{2}, \mathrm{TXB}_{2}$, $\mathrm{PGF}_{2 \alpha}, \mathrm{RvD1}, \mathrm{RvD} 2$, and protectin DX. We can conclude that the method provided similar quantitative performance in plasma for many eicosanoids.

LPS at $10 \mu \mathrm{g} / \mathrm{ml}$ induced $\mathrm{PGE}_{2}$ and $\mathrm{TXB}_{2}$ production in human whole blood, which are the two dominant eicosanoids produced under these conditions (Mazaleuskaya et al., 2016). All other eicosanoids were below the LLOQ. We chose $10 \mu \mathrm{g} / \mathrm{ml}$ of LPS based on the consensus in the literature for this type of assay, yielding a robust amount of $\mathrm{PGE}_{2}(49 \pm 4 \mathrm{ng} / \mathrm{ml}, \mathrm{n}=5$ donors $)$ and $\mathrm{TXB}_{2}(24 \pm 9 \mathrm{ng} / \mathrm{ml}, \mathrm{n}=5$ donors $)$. The prostanoid production was completely blocked using the dual COX-1/2 inhibitor diclofenac $(10 \mu \mathrm{M})$. High concentration of DMSO $(0.1 \%)$ slightly decreased $\mathrm{PGE}_{2}$ production by $20 \%(\mathrm{n}=2$ donors) while DMSO at $0.01 \%$ or $0.001 \%$ had no effect. The intra-assay coefficient of variation $(\mathrm{CV}, \mathrm{n}=20$ technical replicates) was $12 \%$ and $11 \%$ for $\mathrm{PGE}_{2}$ and $\mathrm{TXB}_{2}$, respectively. The inter-assay CV for control material ( $\mathrm{n}=3$ donors) was $20 \%$ for $\mathrm{PGE}_{2}$ and $30 \%$ for $\mathrm{TXB}_{2}$. This was performed on blood that was drawn, incubated, extracted, and analyzed at separate occasions. The suppression in signal due to matrix effects and/ or recovery efficiency varied between donors and experiments, ranging from $10 \%$ to $70 \%$ suppression compared to signal in extracted blank (mean $\pm \mathrm{SD}, \mathrm{n}=6$ donors, $\mathrm{PGE}_{2}: 45 \% \pm 25 \%$, 
$\left.\mathrm{TXB}_{2}: 40 \pm 20 \%\right)$. In summary, 24-h incubation of whole blood with $10 \mu \mathrm{g} / \mathrm{ml}$ LPS resulted in profound induction of the COX-1/ 2 products $\mathrm{PGE}_{2}$ and $\mathrm{TXB}_{2}$ that was efficiently blocked by diclofenac at $10 \mu \mathrm{M}$.

\section{Quantification of IL-8}

IL-8 was quantified in plasma by human IL-8 (CXCL8) enzymelinked immunosorbent assay (ELISA) development kit (3560$1 \mathrm{H}$, Mabtech) according to manufacturer's instructions.

\section{Statistical Analyses}

Data are presented as mean \pm SEM if not stated otherwise. Statistical analyses were performed using GraphPad Prism 6 (GraphPad Software). One-sample t-test and two-sample t-test with Bonferroni correction were used to test significant difference. Statistical significance level was set to $\mathrm{p}<0.05$.

\section{RESULTS}

\section{Effect on $\mathrm{PGE}_{2}$ and $\mathrm{TXB}_{2}$ Production}

Our screening of inhibitors suggested that selected kinase inhibitors affected prostanoid production (Figure 1). The strongest reduction in $\mathrm{PGE}_{2}$ production was observed by MEK-1 inhibitor PD0325901 (31\% $\pm 6 \%, \mathrm{p}=0.001, \mathrm{n}=4)$ and MEK-1/2 inhibitor trametinib $(34 \% \pm 7 \%, \mathrm{p}<0.0001, \mathrm{n}=$ 15). Moderate suppression in $\mathrm{PGE}_{2}$ concentration was found for MEK-1/2 inhibitor selumetinib $(65 \% \pm 9 \%, \mathrm{p}=0.02, \mathrm{n}=5)$, ERK-1/2 inhibitor SCH772984 $(76 \% \pm 11 \%, \mathrm{p}=0.04, \mathrm{n}=13)$, and p38 inhibitor skepinone-L $(76 \% \pm 8 \%, \mathrm{p}=0.01, \mathrm{n}=13)$. However, the tested p38 inhibitor pamapimod did not affect $\mathrm{PGE}_{2}$ production. Two of these compounds decreased $\mathrm{TXB}_{2}$ production, namely trametinib $(63 \% \pm 6 \%, \mathrm{p}=0.02, \mathrm{n}=15)$ and selumetinib $(74 \% \pm 7 \%, \mathrm{p}=0.02, \mathrm{n}=5)$. Diclofenac, here used as a positive control for inhibition of prostanoid production, blocked the prostanoid production while selective COX-2 inhibitor NS-398 inhibited only $\mathrm{PGE}_{2}$ production, in agreement with previously reported data for these compounds in whole blood assay (Larsson et al., 2019). The JAK inhibitor tofacitinib increased both $\mathrm{PGE}_{2}(286 \% \pm 51 \%, \mathrm{p}=0.01, \mathrm{n}=6)$ and $\mathrm{TXB}_{2}(169 \% \pm 20 \%, \mathrm{p}=0.02, \mathrm{n}=6)$ production. The IRAK$1 / 4$ inhibitor I slightly increased the concentrations of $\mathrm{PGE}_{2}$ $(139 \% \pm 15 \%, \mathrm{p}=0.04, \mathrm{n}=7)$ and $\mathrm{TXB}_{2}(133 \% \pm 8 \%, \mathrm{p}=0.008$, $\mathrm{n}=7)$.

We chose to investigate the strongest observed effects in more detail by performing concentration-response experiments for PD0325901, trametinib, selumetinib, and tofacitinib. All three MEK inhibitors showed a concentration-dependent response on both $\mathrm{PGE}_{2}$ and $\mathrm{TXB}_{2}$ production while tofacitinib showed a concentration-dependent response on $\mathrm{PGE}_{2}$ production (Figure 2).

\section{Effect on IL-8 Secretion}

In line with the effect on prostanoid production, reduction in IL-8 secretion was found for PD0325901 (24\% $\pm 9 \%, \mathrm{p}=0.03, \mathrm{n}=3)$, trametinib $(27 \% \pm 5 \%, \mathrm{p}<0.0001, \mathrm{n}=13)$, and selumetinib $(45 \% \pm$ $10 \%, \mathrm{p}=0.03, \mathrm{n}=3$ ) (Figure 3). Moderate reduction in IL-8 secretion was found for SCH772984 $(62 \% \pm 9 \%, \mathrm{p}=0.002, \mathrm{n}=12)$ and diclofenac $(66 \% \pm 8 \%, \mathrm{p}=0.003, \mathrm{n}=11)$. We could also observe that tofacitinib increased IL-8 secretion $(225 \% \pm 57 \%, \mathrm{p}=0.16$, $\mathrm{n}=3$ ), however not with statistical significance.

\section{Effect on LPC Profile}

We measured LPC species within our targeted LC-MS/MS analysis. LPCs are mainly generated by metabolism of membrane phosphatidylcholine by cytosolic phospholipase $\mathrm{A}_{2}$ (Burke and Dennis, 2009). These lipids have been reported to be involved in several cellular processes; sometimes with opposing effect depending on degree of saturation, concentration, and biological context (Sevastou et al., 2013; Drzazga et al., 2014). We observed no difference in total LPC or LPC profile when whole blood was treated with LPS neither did any of the tested inhibitors alter the LPC profile (Figure 4).
A

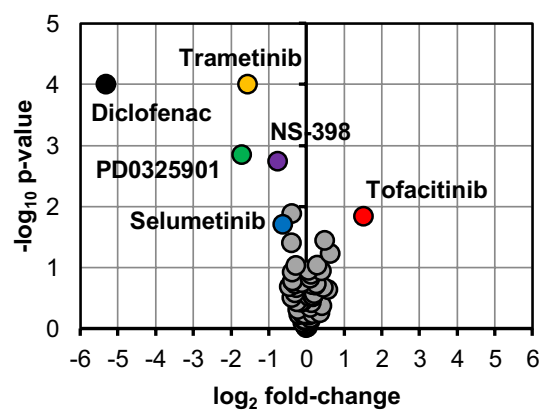

B

Effect on $\mathrm{TXB}_{2}$

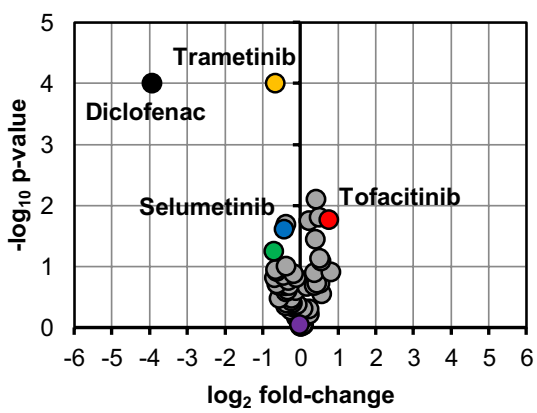

FIGURE 1 | Volcano plots showing effects on $\mathrm{PGE}_{2}$ (A) and TXB 2 (B) production in LPS-induced human whole blood. The top altered conditions compared to vehicle control based on fold-change $(<0.5$ or $>2)$ and $p$-value $(<0.05)$ are highlighted. Each inhibitor was tested in $4-15$ donors. Statistical significance was tested using one-sample t-test $(p<0.05)$. $P G E_{2}$, prostaglandin $E_{2}$; LPS, lipopolysaccharide; $T_{X B_{2}}$, thromboxane $B_{2}$. 

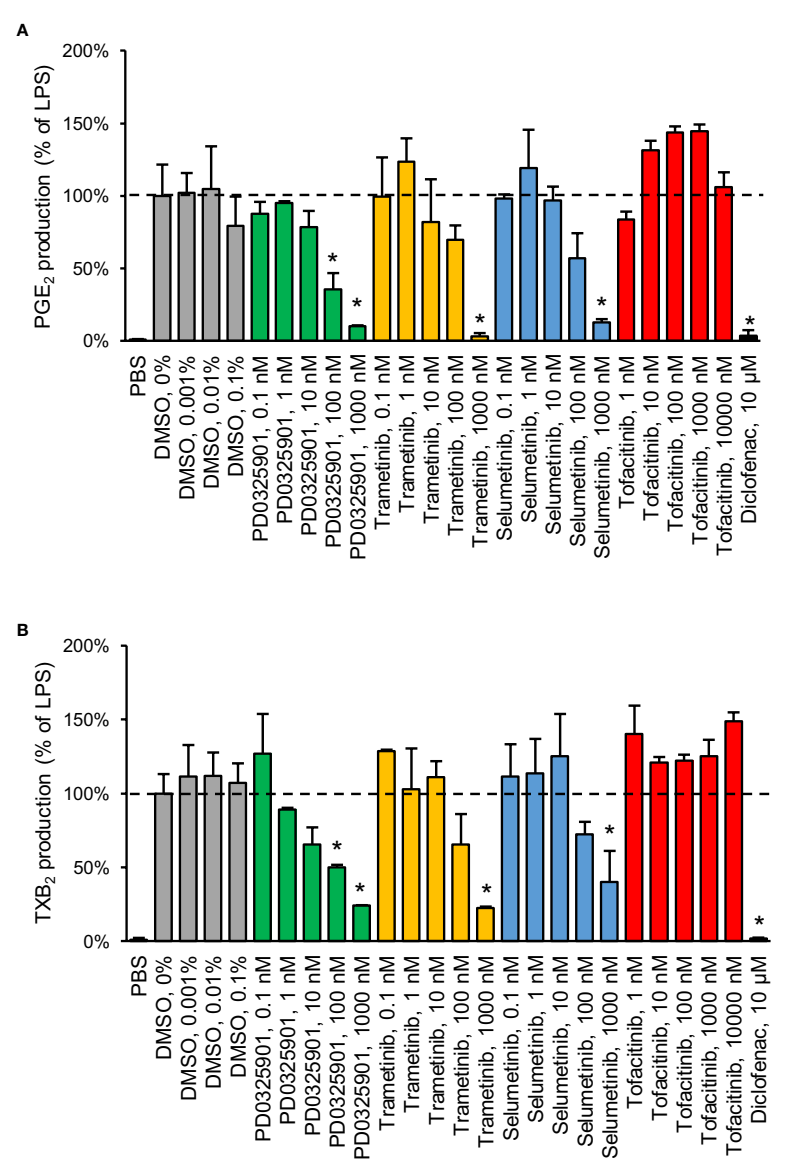

FIGURE 2 | Validation of inhibitory effect on $\mathrm{PGE}_{2}$ (A) and $\mathrm{TXB}_{2}$ (B) production by MEK inhibitors in human whole blood. Diclofenac at $10 \mu \mathrm{M}$ was used as positive control. Data are presented as mean \pm SD of biological replicates ( $n=2-6$ per condition) from one representative experiment. The absolute prostanoid production in LPS control was $53.3 \pm 8.3 \mathrm{ng} / \mathrm{ml}$ for $\mathrm{PGE}_{2}$ and $15.5 \pm 2.1 \mathrm{ng} / \mathrm{ml}$ for $\mathrm{TXB}_{2}$. The concentration-response was tested in two donors. Statistical significance was tested using two-sample t-test with Bonferroni correction $(p<0.05)$. The asterisk $\left({ }^{\star}\right)$ represents statistical significance to vehicle control.

\section{DISCUSSION}

We have tested the inhibitory effect on prostanoid production and IL-8 secretion in human whole blood for 57 high-quality inhibitors with known target specificities and in vitro potencies. None of the tested epigenetic modulators, which are acting on demethylases, bromodomains, or methyltransferases, affected $\mathrm{PGE}_{2}$ or IL-8 concentration. Inhibition of MEK-1/2 or ERK decreased $\mathrm{PGE}_{2}$ production and IL- 8 secretion in this assay. This effect was observed for allosteric inhibitor trametinib (MEK-1/2), non-ATP-competitive inhibitors PD0325901 (MEK-1) and selumetinib (MEK-1/2), and ATP-competitive inhibitor SCH772984 (ERK-1/2). These kinase targets are part of the RAS/RAF/MEK/ERK signaling transduction pathway, where inhibition of MEK prevents the downstream phosphorylation

\section{Effect on IL-8}

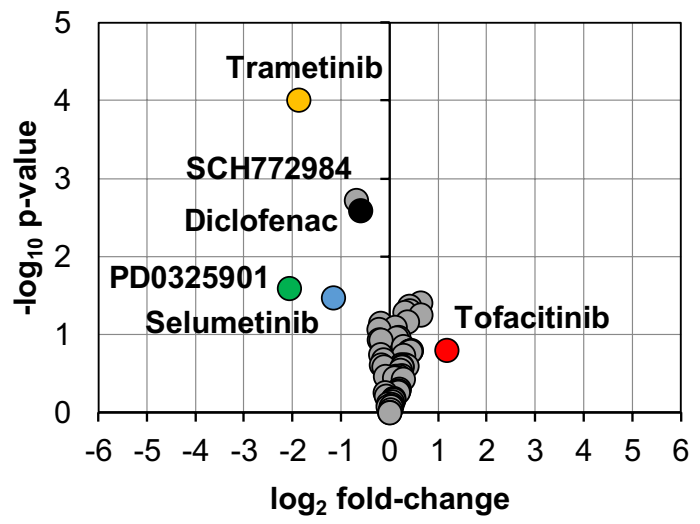

FIGURE 3 | Volcano plot showing effects on IL-8 secretion in LPS-induced human whole blood. The top altered conditions compared to vehicle control based on fold-change $(<0.5$ or $>2)$ and $p$-value $(<0.05)$ are highlighted. Each inhibitor was tested in 3-13 donors. Statistical significance was tested using one sample t-test $(p<0.05)$. IL-8, interleukin-8.

and activation of ERK that ultimately regulates cellular responses such as survival, lipid metabolism, and protein translation (McCubrey et al., 2007). For example, MEK-1/2 inhibitor $\mathrm{PD} 184352$ decreased $\mathrm{PGE}_{2}$ production in melanoma cell line by decreased COX-2 expression due to inhibition of phosphorylation on ERK (Zelenay et al., 2015) and trametinib reduced IL-8 production in melanoma cell line (Hartman et al., 2017). We found that our positive control diclofenac for blocking prostanoid production decreased IL-8 secretion, which is explained by the fact that $\mathrm{PGE}_{2}$ stimulates IL- 8 production in cultured cells (Agro et al., 1996; Caristi et al., 2005; Aso et al., 2012; Venza et al., 2012). While our study mainly focused on identifying inhibitory effects, we observed that JAK inhibitor tofacitinib increased both $\mathrm{PGE}_{2}$ production and IL- 8 secretion. Tofacitinib is used to treat rheumatoid arthritis and it is known that tofacitinib can increase the expression of pro-inflammatory mediators, including $\mathrm{PGE}_{2}$, in macrophages by acting inhibitory on the expression of anti-inflammatory IL-10 (Kothari et al., 2014). The increased formation of pro-inflammatory $\mathrm{PGE}_{2}$ and platelet activating thromboxane $\mathrm{A}_{2}$ (as measured by stable metabolite $\mathrm{TXB}_{2}$ ) in human whole blood may be associated with the recently recognized increased risk of thromboembolism associated with JAK inhibitors in treatment of rheumatoid arthritis (Scott et al., 2018). Moreover, we did not observe any changes in LPC profile by LPS alone or the tested compounds. While LPCs can be generated by degradation of phosphatidylcholine, LPCs are continuously incorporated back into the plasma membrane (Law et al., 2019). This would result in no net change in LPCs while other phospholipid species may change in abundance. We acknowledge that the limitation of our study is the usage of one concentration per tested inhibitor. 
A

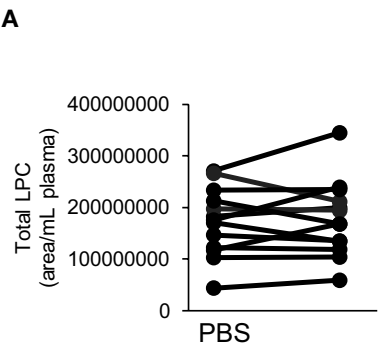

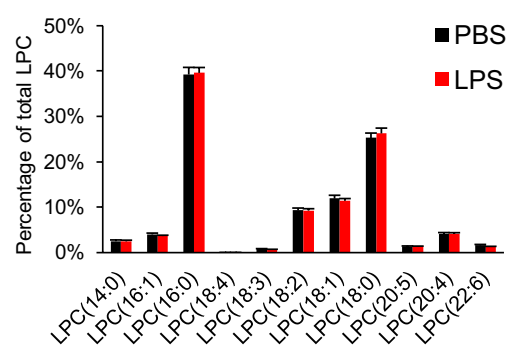

C Total LPC

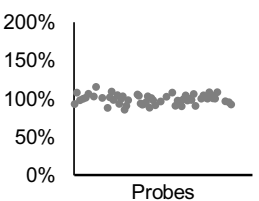

$\operatorname{LPC}(18: 4)$

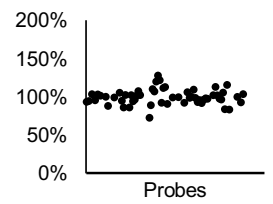

$\operatorname{LPC}(18: 0)$

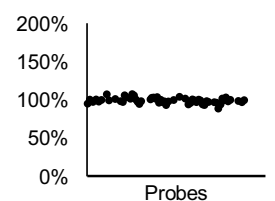

$\operatorname{LPC}(14: 0)$

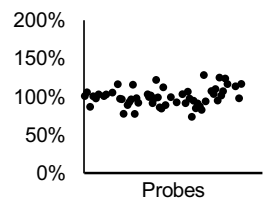

$\operatorname{LPC}(18: 3)$

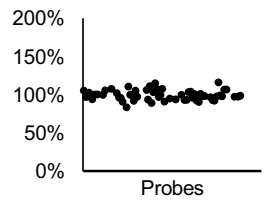

$\operatorname{LPC}(20: 5)$

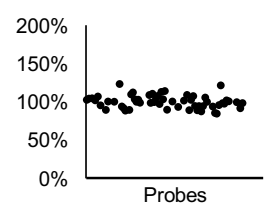

$\operatorname{LPC}(16: 1)$

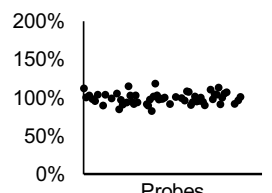

$\operatorname{LPC}(18: 2)$

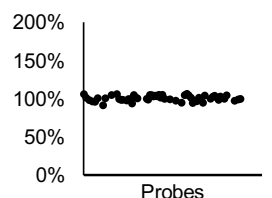

$\operatorname{LPC}(20: 4)$

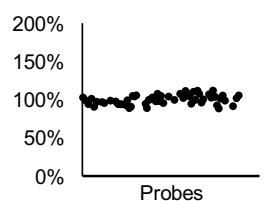

$\operatorname{LPC}(16: 0)$

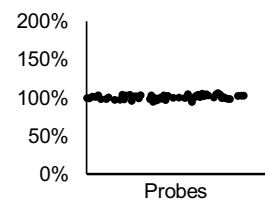

$\operatorname{LPC}(18: 1)$

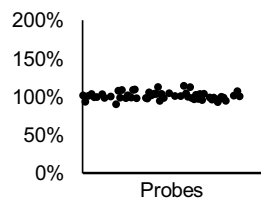

$\operatorname{LPC}(22: 6)$

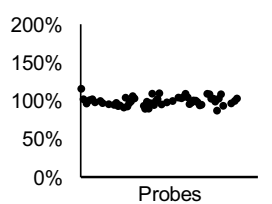

FIGURE 4 | Effect on LPC profile in whole blood. There was no difference in total LPC (A) or LPC profile (B) with LPS treatment, and none of the tested compounds affected the LPC profile (C). Each inhibitor was tested in 4-15 donors. LPC, lysophophatidylcholine.

However, the used concentrations were based on reported $\mathrm{IC}_{50}$ and/or $\mathrm{EC}_{50}$ values as well as solid experiences in our laboratories using other validated assay systems (https://ultra-dd.org/index. $\mathrm{php} /$ tissue-platforms/cell-assay-datasets). The concentrations were selected to avoid cellular toxicity but we acknowledge that greater concentrations might be of relevance considering the bioavailability in blood. Indeed, we demonstrated in concentration-response experiments that greater inhibitory effect could be achieved by increasing the concentration for the MEK inhibitors. However, this increases the risk of off-target effects and/or introduction of cellular toxicity that needs to be taken into account in experimental design and interpretation of results. In conclusion, we identified inhibitors for MEK or ERK as anti-inflammatory hits in our human whole blood assay. Based on the suppression in $\mathrm{PGE}_{2}$ production and IL-8 secretion, further investigation of the MEK/ERK signaling pathway may inform future therapeutic strategies to treat inflammatory diseases such as SLE and DM.

\section{DATA AVAILABILITY STATEMENT}

The datasets generated for this study are available on request to the corresponding authors.

\section{ETHICS STATEMENT}

The studies involving human participants were reviewed and approved by Karolinska University hospital (Dnr 02-196) and the Regional Ethical Review Board in Stockholm (Dnr 2015/ 2001-31/2). The patients/participants provided their written informed consent to participate in this study.

\section{AUTHOR CONTRIBUTIONS}

FB, YS, MS, P-JJ, and LB contributed to study conception and design. FB, YS, and M-MS performed experiments. FB analyzed 
data, performed statistical analysis, and drafted the manuscript. IG and IL facilitated administrative, technical, or material support. All authors critically revised and approved the final version of the manuscript.

\section{ACKNOWLEDGMENTS}

This work was supported by grants from Innovative Medicines Initiative (EU/EFPIA, ULTRA-DD, grant no. 115766), the Swedish Research Council (grant no. 2017-02577), Stockholm County Council (ALF, grant no. 20160378), The Swedish

\section{REFERENCES}

Agro, A., Langdon, C., Smith, F., and Richards, C. D. (1996). Prostaglandin E 2 enhances interleukin 8 (IL-8) and IL- 6 but inhibits GMCSF production by IL-1 stimulated human synovial fibroblasts in vitro. J. Rheumatol 23, 862-868.

Akaogi, J., Nozaki, T., Satoh, M., and Yamada, H. (2012). Role of PGE2 and EP Receptors in the Pathogenesis of Rheumatoid Arthritis and as a Novel Therapeutic Strategy. Endocrine Metab. Immune Disord. - Drug Targets 6, 383-394. doi: 10.2174/187153006779025711

Alfaro, C., Sanmamed, M. F., Rodríguez-Ruiz, M. E., Teijeira, Á., Oñate, C., González, Á., et al. (2017). Interleukin-8 in cancer pathogenesis, treatment and follow-up. Cancer Treat Rev. 60, 24-31. doi: 10.1016/j.ctrv.2017.08.004

Arrowsmith, C. H., Audia, J. E., Austin, C., Baell, J., Bennett, J., Blagg, J., et al. (2015). The promise and peril of chemical probes. Nat. Chem. Biol. 11, 536541. doi: 10.1038/nchembio.1867

Aso, H., Ito, S., Mori, A., Morioka, M., Suganuma, N., Kondo, M., et al. (2012). Prostaglandin e 2 enhances interleukin-8 production via ep4 receptor in human pulmonary microvascular endothelial cells. Am. J. Physiol. - Lung Cell. Mol. Physiol. 302, 266-273. doi: 10.1152/ajplung.00248.2011

Bergqvist, F., Sundström, Y., Shang, M., Gunnarsson, I., Lundberg, I. E., Sundström, M., et al. (2019). Anti-inflammatory properties of chemical probes in human whole blood: focus on prostaglandin E2 production. bioRxiv doi: 10.1101/2019.12.30.890715

Bergqvist, F., Morgenstern, R., and Jakobsson, P. J. (2020). A review on mPGES-1 inhibitors: From preclinical studies to clinical applications. Prostaglandins Other Lipid Mediators 147. doi: 10.1016/j.prostaglandins.2019.106383

Buckley, C. D., Gilroy, D. W., Serhan, C. N., Stockinger, B., and Tak, P. P. (2013). The resolution of inflammation. Nat. Rev. Immunol. 13, 59-66. doi: 10.1038/nri3362

Burke, J. E., and Dennis, E. A. (2009). Phospholipase A 2 structure/function, mechanism, and signaling. J. Lipid Res 50, S237-S242. doi: 10.1194/ jlr.R800033-JLR200

Caristi, S., Piraino, G., Cucinotta, M., Valenti, A., Loddo, S., and Teti, D. (2005). Prostaglandin E2 induces interleukin-8 gene transcription by activating C/EBP homologous protein in human T lymphocytes. J. Biol. Chem. 280, 1443314442. doi: 10.1074/jbc.M410725200

David, J. M., Dominguez, C., Hamilton, D. H., and Palena, C. (2016). The IL-8/IL8R axis: A double agent in tumor immune resistance. Vaccines 4. doi: 10.3390/ vaccines 4030022

Drzazga, A., Sowińska, A., and Koziołkiewicz, M. (2014). Lysophosphatidylcholine and lysophosphatidylinosiol novel promissing signaling molecules and their possible therapeutic activity. Acta Poloniae Pharm. - Drug Res. 71, 887-899.

Fattahi, M. J., and Mirshafiey, A. (2012). Prostaglandins and Rheumatoid Arthritis. Arthritis. 2012, 1-7. doi: 10.1155/2012/239310

Hanahan, D., and Weinberg, R. A. (2011). Hallmarks of cancer: The next generation. Cell 144, 646-674. doi: 10.1016/j.cell.2011.02.013

Hartman, M. L., Rozanski, M., Osrodek, M., Zalesna, I., and Czyz, M. (2017). Vemurafenib and trametinib reduce expression of CTGF and IL-8 in V600EBRAF melanoma cells. Lab. Invest. 97, 217-227. doi: 10.1038/ labinvest.2016.140

Kaplan, M. J. (2011). Neutrophils in the pathogenesis and manifestations of SLE. Nat. Rev. Rheumatol. 7, 691-699. doi: 10.1038/nrrheum.2011.132
Rheumatism Association (grant no. R-755861), King Gustaf V's 80 Years Foundation (grant no. n/a), and funds from Karolinska Institutet (grant no. n/a). This manuscript has been released as a preprint at https://doi.org/10.1101/2019.12.30. 890715, (Bergqvist et al., 2019).

\section{SUPPLEMENTARY MATERIAL}

The Supplementary Material for this article can be found online at: https://www.frontiersin.org/articles/10.3389/fphar.2020. 00613/full\#supplementary-material

Kothari, P., Pestana, R., Mesraoua, R., Elchaki, R., Khan, K. M. F., Dannenberg, A. J., et al. (2014). IL-6-Mediated Induction of Matrix Metalloproteinase-9 Is Modulated by JAK-Dependent IL-10 Expression in Macrophages. J. Immunol 192, 349-357. doi: 10.4049/jimmunol.1301906

Larsson, K., Steinmetz, J., Bergqvist, F., Arefin, S., Spahiu, L., Wannberg, J., et al. (2019). Biological characterization of new inhibitors of microsomal PGE synthase-1 in preclinical models of inflammation and vascular tone. Br. J. Pharmacol 176, 4625-4638. doi: 10.1111/bph.14827

Law, S. H., Chan, M. L., Marathe, G. K., Parveen, F., Chen, C. H., and Ke, L. Y. (2019). An updated review of lysophosphatidylcholine metabolism in human diseases. Int. J. Mol. Sci. 20. doi: 10.3390/ijms20051149

Lit, L. C. W., Wong, C. K., Tam, L. S., Li, E. K. M., and Lam, C. W. K. (2006) Raised plasma concentration and ex vivo production of inflammatory chemokines in patients with systemic lupus erythematosus. Ann. Rheumatic Dis. 65, 209-215. doi: 10.1136/ard.2005.038315

Mao, Y. M., Zhao, C. N., Liu, L. N., Wu, Q., Dan, Y. L., Wang, D. G., et al. (2018). Increased circulating interleukin-8 levels in systemic lupus erythematosus patients: A meta-analysis. Biomarkers Med. 12, 1291-1302. doi: 10.2217/ bmm-2018-0217

Mazaleuskaya, L. L., Lawson, J. A., Li, X., Grant, G., Mesaros, C., Grosser, T., et al. (2016). A broad-spectrum lipidomics screen of antiinflammatory drug combinations in human blood. JCI Insight 1. doi: 10.1172/jci.insight.87031

McCubrey, J. A., Steelman, L. S., Chappell, W. H., Abrams, S. L., Wong, E. W. T., Chang, F., et al. (2007). Roles of the Raf/MEK/ERK pathway in cell growth, malignant transformation and drug resistance. Biochim. Biophys. Acta - Mol. Cell Res. 1773, 1263-1284. doi: 10.1016/j.bbamcr.2006.10.001

McInnes, I. B., and Schett, G. (2011). The pathogenesis of rheumatoid arthritis. New Engl. J. Med. 365, 2205-2219. doi: 10.1056/NEJMra1004965

Nathan, C. (2002). Points of control in inflammation. Nature 420, 846-852. doi: $10.1038 /$ nature 01320

Nielepkowicz-Goździńska, A., Fendler, W., Robak, E., Kulczycka-Siennicka, L., Górski, P., Pietras, T., et al. (2014). Exhaled IL-8 in systemic lupus erythematosus with and without pulmonary fibrosis. Archivum Immunologiae Ther. Exp. 62, 231-238. doi: 10.1007/s00005-014-0270-5

Peng, Y., Zhang, S., Zhao, Y., Liu, Y., and Yan, B. (2018). Neutrophil extracellular traps may contribute to interstitial lung disease associated with anti-MDA5 autoantibody positive dermatomyositis. Clin. Rheumatol. 37, 107-115. doi: 10.1007/s10067-017-3799-y

Ricciotti, E., and Fitzgerald, G. A. (2011). Prostaglandins and inflammation. Arteriosclerosis Thrombosis Vasc. Biol. 31, 986-1000. doi: 10.1161/ ATVBAHA.110.207449

Russo, R. C., Garcia, C. C., Teixeira, M. M., and Amaral, F. A. (2014). The CXCL8/ IL-8 chemokine family and its receptors in inflammatory diseases. Expert Rev. Clin. Immunol. 10, 593-619. doi: 10.1586/1744666X.2014.894886

Scott, I. C., Hider, S. L., and Scott, D. L. (2018). Thromboembolism with Janus Kinase (JAK) Inhibitors for Rheumatoid Arthritis: How Real is the Risk? Drug Safety 41, 645-653. doi: 10.1007/s40264-018-0651-5

Sevastou, I., Kaffe, E., Mouratis, M. A., and Aidinis, V. (2013). Lysoglycerophospholipids in chronic inflammatory disorders: The PLA 2/ LPC and ATX/LPA axes. Biochim. Biophys. Acta - Mol. Cell Biol. Lipids 1831, 42-60. doi: 10.1016/j.bbalip.2012.07.019 
Venza, I., Visalli, M., Fortunato, C., Ruggeri, M., Ratone, S., Caffo, M., et al. (2012). PGE2 induces interleukin-8 derepression in human astrocytoma through coordinated DNA demethylation and histone hyperacetylation. Epigenetics 7, 1315-1330. doi: 10.4161/epi.22446

Wang, D., and Dubois, R. N. (2010). Eicosanoids and cancer. Nat. Rev. Cancer 10, 181-193. doi: $10.1038 / \mathrm{nrc} 2809$

Waugh, D. J. J., and Wilson, C. (2008). The interleukin-8 pathway in cancer. Clin. Cancer Res. 14, 6735-6741. doi: 10.1158/1078-0432.CCR-07-4843

Yoshio, T., Okamoto, H., Kurasawa, K., Dei, Y., Hirohata, S., and Minota, S. (2016). IL-6, IL-8, IP-10, MCP-1 and G-CSF are significantly increased in cerebrospinal fluid but not in sera of patients with central neuropsychiatric lupus erythematosus. Lupus 25, 997-1003. doi: 10.1177/ 0961203316629556

Zelenay, S., Van Der Veen, A. G., Böttcher, J. P., Snelgrove, K. J., Rogers, N., Acton, S. E., et al. (2015). Cyclooxygenase-Dependent Tumor Growth through Evasion of Immunity. Cell 162, 1257-1270. doi: 10.1016/j.cell.2015.08.015

Zhang, S., Shu, X., Tian, X., Chen, F., Lu, X., and Wang, G. (2014). Enhanced formation and impaired degradation of neutrophil extracellular traps in dermatomyositis and polymyositis: A potential contributor to interstitial lung disease complications. Clin. Exp. Immunol. 177, 134-141. doi: 10.1111/ cei. 12319
Conflict of Interest: The SGC receives funds from AbbVie, Bayer Pharma, Boehringer Ingelheim, the Canada Foundation for Innovation, the Eshelman Institute for Innovation, Genome Canada, Janssen, Merck (Darmstadt, Germany), MSD, Novartis Pharma, the Ontario Ministry of Economic Development and Innovation, Pfizer, the São Paulo Research Foundation, Takeda and the Wellcome Trust (authors: FB, YS, M-MS, MS, P-JJ, and LB). These funders had no direct role in study conceptualization, design, data collection, analysis, decision to publish, or preparation of the manuscript. P-JJ is member of the board of directors at Gesynta Pharma, a company that develops anti-inflammatory drugs.

The remaining authors declare that the research was conducted in the absence of any commercial or financial relationships that could be construed as a potential conflict of interest.

Copyright (c) 2020 Bergqvist, Sundström, Shang, Gunnarsson, Lundberg, Sundström, Jakobsson and Berg. This is an open-access article distributed under the terms of the Creative Commons Attribution License (CC BY). The use, distribution or reproduction in other forums is permitted, provided the original author(s) and the copyright owner(s) are credited and that the original publication in this journal is cited, in accordance with accepted academic practice. No use, distribution or reproduction is permitted which does not comply with these terms. 